\title{
1 Problems with comparative analyses of avian brain size
}

2 Rebecca Hooper ${ }^{1,2}$, Becky Brett ${ }^{1}$, Alex Thornton $^{1 *}$

3

4

5

6

\section{$7 \quad$ Abstract}

${ }^{1}$ University of Exeter, Centre for Ecology and Conservation, Penryn Campus, Cornwall, UK

${ }^{2}$ University of Exeter, Department of Psychology, Streatham Campus, Exeter, UK

Corresponding authors: r.c.hooper2@exeter.ac.uk; alex.thornton@exeter.ac.uk

There are multiple hypotheses for the evolution of cognition. The most prominent hypotheses are the Social Intelligence Hypothesis (SIH) and the Ecological Intelligence Hypothesis (EIH), which are often pitted against one another. These hypotheses tend to be tested using broad-scale comparative studies of brain size, where brain size is used as a proxy of cognitive ability, and various social and/or ecological variables are included as predictors. Here, we test how methodologically robust such analyses are. First, we investigate variation in brain and body size measurements across $>1000$ species of bird. We demonstrate that there is substantial variation in brain and body size estimates across datasets, indicating that conclusions drawn from comparative brain size models are likely to differ depending on the source of the data. Following this, we subset our data to the Corvides infraorder and interrogate how modelling decisions impact results. We show that model results change substantially depending on variable inclusion, source and classification. Indeed, we could have drawn multiple contradictory conclusions about the principal drivers of brain size evolution. These results reflect recent concerns that current methods in comparative brain size studies are not robust. We add our voices to a growing community of researchers suggesting that we move on from using such methods to investigate cognitive evolution. We suggest that a more fruitful way forward is to instead use direct measures of cognitive performance to interrogate why variation in cognition arises within species and between closely related taxa.

\section{Introduction}

The principal drivers of cognitive evolution have been debated for decades (Ashton et al., 2020; Barton, 1996; Dunbar, 1992; Dunbar \& Shultz, 2017; Holekamp, 2007; Humphrey, 1976; Jolly, 1966; Rosati, 2017). Researchers often fall into two broad camps, focusing 
primarily on either social or ecological factors. Briefly, the Social Intelligence Hypothesis (SIH) posits that cognitive evolution is principally driven by the informational challenges of navigating a dynamic social environment, such as the need to track, anticipate and respond to the behaviour of social partners, and monitor the relationships of others (Byrne \& Whiten, 1988; Dunbar, 1998; Humphrey, 1976; Jolly, 1966). In contrast, the Ecological Intelligence Hypothesis (EIH) and its variants emphasise informational challenges posed by ecological variables, such as variable food sources and climatic conditions (Allman et al., 1993; Barton, 1996; Clutton-Brock \& Harvey, 1980; Deaner et al., 2003; Harvey \& Krebs, 1990). A large body of research has investigated social and ecological correlates of brain size (Chen et al., 2021; DeCasien et al., 2017; Dunbar, 1992; Iwaniuk, 2004; MacLean et al., 2009; PérezBarbería et al., 2007; Sayol et al., 2016; Shultz \& Dunbar, 2007; Street et al., 2017; van Woerden et al., 2010; West, 2014), but results are often inconsistent and contradictory (Healy \& Rowe, 2007; Iwaniuk, 2004; Logan et al., 2018; Powell et al., 2017; Wartel et al., 2019). For instance, Dunbar (1992), found that primate social group size positively correlated with a measure of brain size, which is commonly used as a proxy for cognitive ability. In contrast, DeCasien et al. (2017) found that diet is an important driver of primate brain size but social group size is not. Wartel et al. (2019), on the other hand, found that either diet or social group size could predict primate brain size, depending on where brain size data and predictor variables were sourced from. While most research interrogating the SIH and EIH has focused on primates, birds have emerged as a major model system in cognitive evolution over the last 20 years (Güntürkün \& Bugnyar, 2016; Iwaniuk \& Arnold, 2004; Overington et al., 2009; Sayol et al., 2016; Seed et al., 2009). Some species of bird show convergent cognitive performance to primates (Güntürkün \& Bugnyar, 2016; Seed et al., 2009), yet birds have divergent neuroanatomy (Güntürkün \& Bugnyar, 2016) and differing constraints on brain size, such as those imposed by long-range migration (Vincze, 2016). Here we interrogate the potential pitfalls that arise in the comparative study of cognitive evolution in birds. Moreover, we highlight potential pitfalls of current methodologies that have not yet been investigated in any taxa.

The relationship between brain size and cognitive ability is largely unknown and highly contentious (Chittka \& Niven, 2009; Healy \& Rowe, 2007; Logan et al., 2018). Nevertheless, studies investigating comparative cognitive evolution very often use some measure of brain size as a proxy of cognitive ability (Wartel et al., 2019). Most comparative studies of brain size use a single measurement of brain size per species, taken either from a single "type 
specimen" individual or averaged across multiple individuals. The influence of intra-specific variation in brain size on the results of comparative analyses are therefore poorly understood. Moreover, to control for the allometric relationship between brain and body size, most studies of brain size control for body size ('relative brain size') (Logan et al., 2018). However, the impact that intraspecific variation in body size estimates may have on analyses of relative brain size has not been investigated. Here, we collate data from multiple datasets of brain and body size to interrogate how estimates vary across datasets. Given that most comparative studies of brain size use only one estimate of brain and body size, variation in estimates has the potential to substantially change results.

The approach that researchers take toward model specification may also considerably influence results. While most studies utilise similar statistical techniques to test hypotheses of brain size evolution, approaches toward model specification differ. Indeed, some researchers opt to include covariates associated only with the hypothesis of interest (broadly, the SIH or EIH), and either omit (e.g., Emery et al., 2007) or include less detailed (e.g. Chen et al., 2021; Sayol et al., 2016) variables associated with the competing hypothesis. However, the combination of variables is known to have a substantial influence on the results of primate brain size models (Powell et al., 2017; Wartel et al., 2019). In addition, where covariates are sourced from can have a substantial impact on results. For instance, Wartel et al. (2019) showed that changing the source from which covariates (e.g. diet) were collected substantially changed the results of a previous study (DeCasien et al., 2017). Moreover, decisions on how to define variables can be a somewhat subjective decision made by authors, and this may also have a significant influence on results. For example, if some populations of a species are migratory, but most are resident, should the species be classified as migrant, resident, or a different category altogether, in which case small sample sizes per category may become a concern? How such classification decisions influence model results is, as yet, unquantified.

Here, we use multiple datasets of brain and body size to quantify variation in estimates for more than 1000 species of bird. Following this, we interrogate whether conclusions drawn from models testing alternative hypotheses for brain size evolution differed depending on the combination, source and classification of variables included. To do this, we collated detailed social and ecological variables for species in the Corvides infraorder. The Corvides are wellsuited to this investigation because they have a well-resolved phylogeny (Jønsson et al., 2016), large variation in brain size (Iwaniuk \& Arnold, 2004), and the majority of species 
have known social and ecological variables. In addition, focusing on a group of closely related taxa helps to mitigate the potentially confounding effect of differing brain and body size allometries between distantly related taxa (Ksepka et al., 2020; Logan et al., 2018). Together, these investigations allow us to (i) identify novel pitfalls in the study of comparative cognition, and (ii) highlight parallel pitfalls to those previously identified in the field of primate comparative cognition (Powell et al., 2017; Wartel et al., 2019).

\section{Methods}

Quantifying intraspecific variation in brain and body size Whole brain volumes across bird species were collated from six published datasets (Corfield et al., 2013; García-Peña et al., 2013; Iwaniuk et al., 2005; Iwaniuk \& Arnold, 2004; Iwaniuk \& Nelson, 2003; Sayol et al., 2016), all of which recorded brain volume using either the endocranial volume technique (see Iwaniuk \& Nelson, 2002 for details), brain mass converted to volume (Iwaniuk \& Nelson, 2002), or both. These datasets are non-independent, with some measurements shared between them. Each dataset reported one datapoint per species, with the exception of García-Peña et al. (2013) who reported two datapoints per species (one female, one male) and their associated standard errors (where more than one type specimen per sex was used).

Body sizes were collated from eleven published datasets from ten studies (Corfield et al., 2013; Fristoe et al., 2017; Garamszegi et al., 2002; Iwaniuk et al., 2004, 2005; Iwaniuk \& Arnold, 2004; Lendvai et al., 2013; Minias \& Podlaszczuk, 2017; Sayol et al., 2016; Sol et al., 2010). One study collated two independently collected sources of body mass data (Minias \& Podlaszczuk, 2017) and these were thus treated as two different datasets. All body sizes were measured in grams. Again, datasets are not independent, with some using overlapping sources. Each dataset had one datapoint per species; one dataset recorded standard errors associated with the estimate (Garamszegi et al., 2002).

Influence of variable inclusion, classification and source We tested whether including detailed ecological and social covariates, relative to including ecological or social covariates, qualitatively changed conclusions of models. To do this, we extracted/collated detailed ecological and social variables that have previously been shown to have a significant relationship with brain size (see Methods: Variables). In addition to constructing models with differing sets of predictor variables, we examined how sensitive model results were to choices regarding the classification of variables (see Methods: Variables: Re-classification). 
We also tested whether collecting variables from differing sources changed model results (see Methods: Variables: Environmental variation).

Variables We extracted/collated the following detailed ecological and social variables that have previously been shown to have a significant relationship with brain size.

1. Ecological variables We included species movement, environmental variability and diet. Species that migrate are thought to have smaller brains than resident species (Pravosudov et al., 2007; Shultz \& Dunbar, 2010; Sol et al., 2010; Vincze, 2016). This is hypothesised to be because the energetic cost of the brain constrains selection on increased brain size in migrating species, who have large energetic demands during migration (Pravosudov et al., 2007; Sol et al., 2010; Vincze, 2016). Meanwhile, species that live in fluctuating environments (Fristoe et al., 2017; Sayol et al., 2016; Schuck-paim et al., 2008) and species with broader diets (Sayol et al., 2016) are thought to have bigger brains than those in more stable environments or with specialist diets. This is potentially because species that encounter more ecological uncertainty must process more information in order to respond appropriately (Dall et al., 2005; Sayol et al., 2016; Schmidt et al., 2010), and therefore require more 'processing power' (i.e., bigger brains, assuming bigger brains to be a proxy of better cognitive ability).

1.1 Movement We coded species movement using four categories: resident, partial migrant, migrant or nomadic. Previous studies including migration as a covariate tend to include migration as a binary variable (resident or migratory: Fristoe et al., 2017; Shultz \& Dunbar, 2010). However, some species are only migratory in certain regions. Such species were therefore coded as partial migrants (but see Methods: Variables: Re-classification). Meanwhile, other species are neither migrants nor residents and can instead be considered nomadic.

1.2 Environmental variability We collected environmental variability from two sources. The first measure of environmental variability was 'temperature variation', as reported in Fristoe et al., 2017, where higher values indicate more variability. The second was a measure of environmental variability calculated by Sayol et al. (2016). Briefly, Sayol et al. included multiple environmental variables in a phylogenetic principal component analysis. The resultant phylogenetic principal component 1 (PPC1) captured seasonal variation, duration of snow cover and among-year variation, with higher values indicating higher variation, longer snow-cover and larger among-year variation. PPC1 can therefore be interpreted as an axis 
describing general environmental variation. Meanwhile, phylogenetic principal component 2 (PPC2) captured environmental variation at lower latitudes (e.g., drought events).

Temperature variation and PPCs were never used in the same models; instead, they were interpreted as two independent sources of 'environmental variation', which we used to quantify whether differing variable source may influence results.

1.3 Diet breadth We used diet breadth as reported in Sayol et al. (2016) who used Rao's quadratic entropy (de Cáceres et al., 2011) with diet frequency for seven diet types. Higher values indicate a broader diet.

2. Social variables We used two social variables in our models, both of which have been suggested to be involved in brain size evolution: social foraging and cooperative breeding. While long-term monogamy has been shown to positively correlate with brain size in some studies (Emery et al., 2007; Shultz \& Dunbar, 2010), almost all species in our sample form long-term monogamous pair bonds (see Supplementary Data) so there was not enough variation for this variable to be included.

\subsection{Social foraging Foraging group structure has previously been shown to correlate with} relative brain size (Emery et al., 2007; Shultz \& Dunbar, 2010). Specifically, species that forage in pairs or bonded groups have been shown to have larger brains than those that forage in large aggregations (Shultz \& Dunbar, 2010). Similarly, species that live in small groups have been shown to have bigger brains than those that live in large aggregations (Emery et al., 2007). This is argued to be because the quality rather than quantity of social bonds is a key driver of cognitive evolution in birds (Emery et al., 2007; Shultz \& Dunbar, 2010). However, in other studies foraging group structure appears to be unimportant (Sayol et al., 2016). A common problem with the inclusion of social variables in comparative studies is that they may not capture the underlying informational demands which, according to the SIH, drive cognitive evolution (Boucherie et al., 2019; Dunbar, 1998; Lukas \& Clutton-Brock, 2018). We therefore expanded on previous categorisations of foraging group structure by trying to capture variables thought to be associated with information-processing. Specifically, species were coded as foraging solitarily, in pairs, in small groups ( $<30$ individuals), in aggregations (>30 individuals), or as nested versions of these variables (e.g., forages in pairs nested within larger groups). If a species is known to forage in different social contexts but not necessarily in a nested fashion, we categorised these species using the largest group size commonly recorded (e.g., if the species forages in pairs and in small groups, but not 
necessarily in a nested manner, we recorded this as small group foraging). Following predictions of the SIH, we expected that solitary foragers would have the smallest brains, given the relatively limited demands for processing social information. Moreover, we expected that species foraging in nested groups would generally have larger brains, given the informational demands of managing relationships within a multi-layered context (e.g., managing the pair-bond relationship within a wider social group).

\subsection{Cooperative breeding The role of cooperative breeding in cognitive evolution is} contentious. Some authors argue that cooperative breeding entails substantial cognitive demands because individuals need to cooperate and coordinate with multiple others to raise offspring (Burkart et al., 2009; Burkart \& van Schaik, 2009; Hrdy, 2009). Conversely, others suggest that the typically high levels of relatedness and shared interests within cooperatively breeding groups may in fact reduce cognitive demands relative to independent breeding (Lukas \& Clutton-Brock, 2018; Thornton et al., 2016; Thornton \& McAuliffe, 2015). Relevant empirical evidence remains limited and controversial. For instance, Burkart \& van Schaik (2009) suggest that cooperatively breeding monkeys show elevated socio-cognitive performance, but these species also have particularly small brains (Thornton \& McAuliffe, 2015), and rank poorly in meta-analyses of cognitive performance across primates (Deaner et al., 2006). Among birds, the only comparative study to date found no relationship between cooperative breeding and brain size (Iwaniuk \& Arnold, 2004), but this study did not include variables since shown to be significantly related to brain size, such as diet and environmental variation (Sayol et al., 2016). We therefore included cooperative breeding as a binary variable in our analyses. We note that species such as American crows (Corvus brachyrhynchos) and carrion crows (Corvus corone) are facultative cooperative breeders, but as there were few species in our sample that could be defined as such, we classified all facultative cooperative breeders as cooperative (but see Methods: Variables: Re-classification).

Re-classification Some classifications are ambiguous and multiple different classifications can be justified. We therefore tested whether re-classifying variables changed model results. We re-classified one ecological and one social variable. "Partial migrants", where at least one population of a species migrates but other populations are resident, were re-classified as residents. Facultative or suspected cooperative breeders were re-classified as non-cooperative breeders, rather than cooperative breeders. 
Statistical modelling All statistical analyses were undertaken in R v4.0.2 (R Core Team 2017). We used a phylogenetic generalized least squares (PGLS) modelling framework (Freckleton et al., 2002) in the package caper (Orme, 2018), which controls for nonindependence of datapoints due to relatedness. We used this method because it is the most commonly used technique in the comparative brain size literature (e.g. Fristoe et al., 2017; Fristoe \& Botero, 2019; Sayol et al., 2016; Shultz \& Dunbar, 2010; Sol et al., 2010; Vincze, 2016). We constructed a consensus tree by downloading 1000 equally plausible phylogenetic trees for the species in our sample from www.BirdTree.org (Sayol et al., 2016). We used the Hackett rather than Ericson backbone because it is the most recently constructed; however, differences between backbones are small and they tend to produce consistent results (Rubolini et al., 2015). Using TreeAnnotator in BEAST v1.10.4, a maximum clade credibility consensus tree was built from these equally plausible trees. This tree was then used to control for phylogenetic non-independence in the following PGLS models. Lambda was estimated using Maximum Likelihood. Model diagnostics and variance inflation factor (VIF) were checked to ensure assumptions were met and variables were not unacceptably collinear, respectively.

Corvides analysis Here, we tested how variable combination, source (environmental variability: temperature variation or PPC) and classification (partial migrant/resident; cooperative breeder/non-cooperative breeder) changed conclusions. See Table 1 for a summary of model formulations. We used Sayol et al.'s (2016) brain size data only. We chose to use this dataset because only one method was used to measure brain size, and all body mass data came from the same specimens that brain volume was taken from. It is therefore likely to be the most precise data currently available. Using this data, we built three models: an SIH model (brain size in response to body size, cooperative breeding and social foraging), an EIH model (brain size in response to body size, migration, environmental variability and diet breadth), and a 'combined' model with all covariates included. For the EIH model, we tested two sources of environmental variation: temperature variation (Fristoe et al., 2017) and PPCs (Sayol et al., 2016). We used temperature variation as the measure of environmental variation in the combined model because the limited number of species with PPC data available resulted in some social foraging categories having extremely limited sample sizes. We tested 'initial' and 'reclassified' variables for species movement and cooperative breeding across all models. Brain and body size measurements were logtransformed. 


\section{Results}

257 Quantifying intraspecific variation in brain and body size Altogether we collated brain size

258 data for 1484 bird species. Of these, 1054 species had brain measurements in more than one

259 dataset. Figure 1a visualises variation in log-transformed brain size estimates across datasets.

260 All but one of the collated datasets had one brain size estimate per species; we therefore

261 present García-Peña's sex-separated data as sex-averaged in Figure 1a. Only two of the five

262 studies that did not measure sexes separately explicitly stated that brain size datapoints were

263 sex-averaged (Iwaniuk \& Arnold, 2004; Sayol et al., 2016). While brain size estimates tended

264 to be the mean value of multiple specimens (on average, $\sim$ six specimens per species), ten or

265 more brain size estimates were based on a single type speciman in at least two studies

266 (Corfield et al., 2013; Iwaniuk et al., 2005).

267 Across datasets, some species varied considerably in brain size estimate (Figure 1a). For 268 instance, the minimum and maximum brain size estimates of Pyrrhura frontalis (with the 269 largest overall difference in estimates) overlapped with the brain size estimates of 161 other species in our full sample of 1484 species (10.85\%). Similarly, Acanthorhynchus tenuirostris'

a

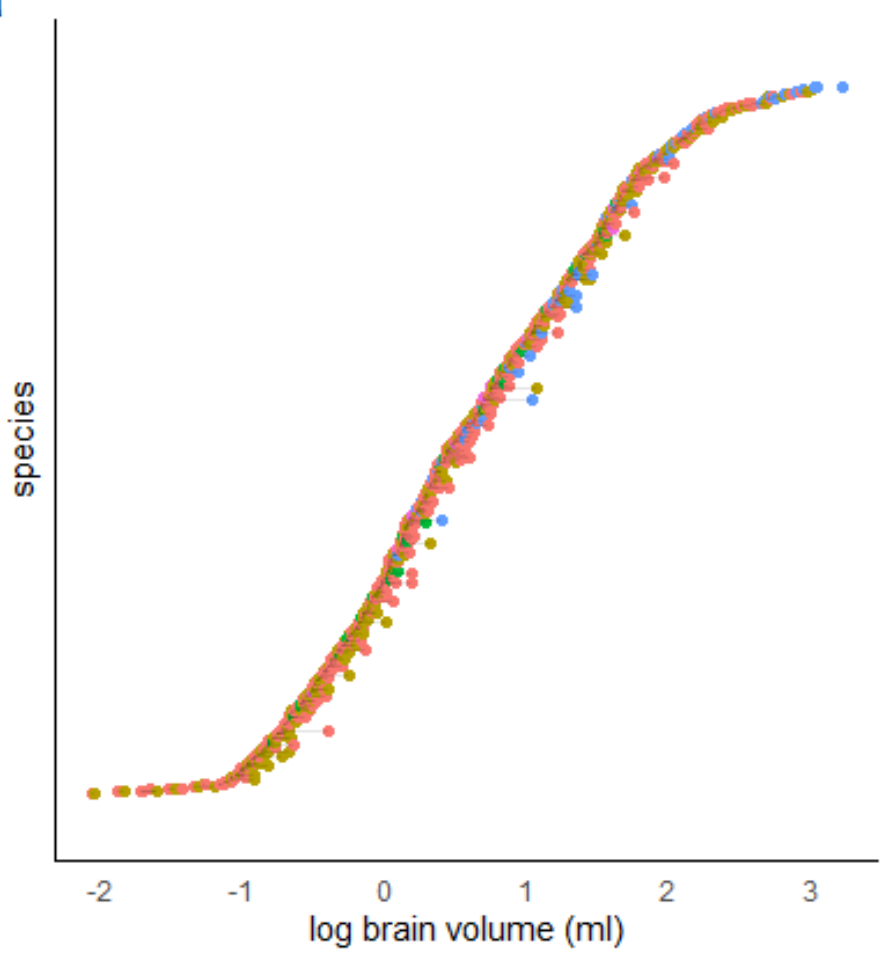

b

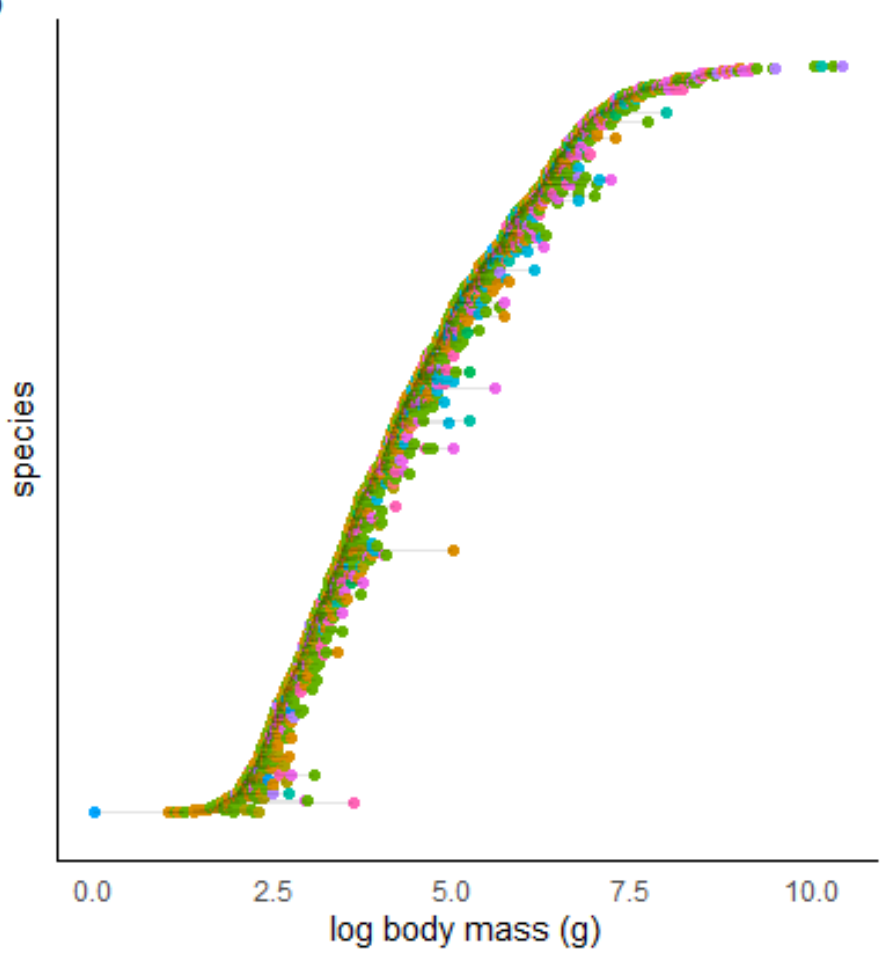

Figure 1a Log brain volume $(\mathrm{ml})$ per species. Only species with brain size estimates in two or more datasets are included $(\mathrm{n}=1054)$. 1b Log body mass $(\mathrm{g})$ per species. Again, only species with body mass estimates in two or more datasets are included $(\mathrm{n}=1578)$. In both $\mathbf{1 a}$ and $\mathbf{1 b}$, species are ordered by minimum brain size. Grey lines connect estimates for the same species, which always correspond to estimates from different datasets. Point colour is associated with the source dataset $(\mathrm{n}=6$ for $\mathbf{1 a}, \mathrm{n}=11$ for $\mathbf{1 b})$. 
minimum and maximum estimates (with the second largest absolute difference) overlapped with 150 species (10.11\% of our sample) and Tinamus major's estimates (the third largest absolute difference) overlapped with 143 species (9.64\% of our sample). Variation was not driven by any one dataset in particular (Figure 1a).

Our collated body size dataset contained 2398 species from eleven datasets. 1578 of these species had body mass measurements in more than one dataset. There was a general paucity of details for body mass data. Only one of 11 studies explicitly reported the number of samples from which body mass estimate was calculated (Garamszegi et al., 2002). Only two of 11 explicitly stated that body mass estimates were sex-averaged (Lendvai et al., 2013; Minias \& Podlaszczuk, 2017). Ten of the eleven datasets recorded both brain size and body mass data; however, only three of these sometimes collected body mass from the same specimens as brain size (Corfield et al., 2013; Iwaniuk \& Arnold, 2004; Sol et al., 2010) and only two always collected body mass from the same specimens as brain size (Garamszegi et al., 2002; Sayol et al., 2016). Three studies did not mention the primary sources of the body mass data used (Iwaniuk et al., 2004, 2005; Lendvai et al., 2013).

Figure $1 \mathrm{~b}$ visualises variation in log-transformed body mass estimates across datasets. Again, some species varied considerably in body mass estimates. For instance, the minimum and maximum body mass estimates of Malurus pulcherrimus (with the largest overall difference in estimates) overlapped with the body mass estimates of 146 other species in our full sample of 2398 species (6.09\%). Similarly, Alauda arvensis' minimum and maximum estimates (with the second largest absolute difference) overlapped with 786 species (32.78\% of our sample) and Charadrius tricollaris' estimates (the third largest absolute difference) overlapped with 781 species ( $32.57 \%$ of our sample). In parallel to the brain size data, variation was not primarily driven by any one dataset (Figure 1b).

Corvides analysis (Table 1; Table 2; Figure 2) The full dataset used for this analysis included 59 species, where all species had known social and ecological variables (excluding PPCs). The PPC subset contained 46 species. Conclusions on the principal drivers of brain size evolution in Corvides differed depending on modelling approach (see Table 1 for a general summary; Table 2 and Figure 2 for model results).

In the EIH model with temperature variation included, species movement was significantly associated with brain size. Specifically, resident species were found to have bigger brains than nomadic species. In the EIH model with PPCs (one measure of environmental variation) 
303

304

305

306

307

308

309

rather than temperature variation (a different measure of environmental variation) included, both PPC1 and PPC2 were significantly associated with brain size. However, species movement was not. Thus, depending on where we sourced our measure of environmental variation, we could have concluded that environmental variation drives brain size and species movement does not or, indeed, the exact opposite.

Table 1 Different models testing a specific hypothesis (SIH/EIH) to test how variable inclusion changes conclusions drawn from results.

\begin{tabular}{|c|c|c|c|}
\hline Hypothesis & Species number & Model predictors & Conclusions \\
\hline $\begin{array}{l}\text { Ecological } \\
\text { Intelligence } \\
\text { Hypothesis (EIH) }\end{array}$ & 59 & $\begin{array}{l}\text { body size }+ \text { diet } \\
\text { breadth }+ \\
\text { environmental } \\
\text { variation (temperature } \\
\text { variation) }+ \\
\text { movement }\end{array}$ & $\begin{array}{l}\text { 1. Species movement correlates } \\
\text { with brain size (residents have } \\
\text { bigger brains than nomads) } \\
\text { 2. Environmental variation does } \\
\text { not correlate with brain size }\end{array}$ \\
\hline EIH (PPC) & 46 & $\begin{array}{l}\text { body size }+ \text { diet } \\
\text { breadth }+ \\
\text { environmental } \\
\text { variation }(\boldsymbol{P P C 1}+ \\
\boldsymbol{P P C 2})+ \text { movement }\end{array}$ & $\begin{array}{l}\text { 1. Species movement is not } \\
\text { correlated with brain size } \\
\text { 3. Environmental variation } i s \\
\text { correlated with brain size: } \\
\text { more environmental variation } \\
\text { correlates with bigger brains }\end{array}$ \\
\hline $\begin{array}{l}\text { Social Intelligence } \\
\text { Hypothesis (SIH) }\end{array}$ & 59 & $\begin{array}{l}\text { body size }+ \\
\text { cooperative breeding }+ \\
\text { social foraging }\end{array}$ & $\begin{array}{l}\text { 1. Social foraging correlates with } \\
\text { brain size (species that forage } \\
\text { in non-nested small groups } \\
\text { have bigger brains than those } \\
\text { that forage in pairs) }\end{array}$ \\
\hline $\begin{array}{l}\text { Combined (EIH + } \\
\text { SIH) }\end{array}$ & 59 & $\begin{array}{l}\text { body size }+ \text { diet } \\
\text { breadth }+ \\
\text { environmental } \\
\text { variation (temperature } \\
\text { variation) + } \\
\text { movement + } \\
\text { cooperative breeding }+ \\
\text { social foraging }\end{array}$ & $\begin{array}{l}\text { 1. Species movement correlates } \\
\text { with brain size (residents have } \\
\text { bigger brains than nomads) } \\
\text { 2. Social foraging correlates with } \\
\text { brain size (species that forage } \\
\text { in non-nested small groups } \\
\text { and solitarily have bigger } \\
\text { brains than those that forage in } \\
\text { pairs) }\end{array}$ \\
\hline
\end{tabular}


bioRxiv preprint doi: https://doi org/10.1101/2021.1125,469898; this version posted November 29, 2021. The copyright holder for this preprint (which was not certified by peer review) is the author/funder, who has granted bioRxiv a license to display the preprint in perpetuity. It is made available under aCC-BY-NC-ND 4.0 International license.

Table 2 Phylogenetic Generalised Least Squares model results, comparing different model formulations. All significant pairwise contrasts for categorical variables are presented.

\begin{tabular}{|c|c|c|c|c|c|c|}
\hline Model type & Predictors & $\lambda$ & Estimate & Standard error & $\begin{array}{l}\text { T- } \\
\text { value }\end{array}$ & $\begin{array}{l}P \text { - } \\
\text { value }\end{array}$ \\
\hline \multirow{6}{*}{ EIH } & Body size & \multirow{6}{*}{ 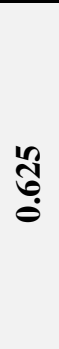 } & 0.663 & 0.03 & 22.434 & $<0.001$ \\
\hline & Diet breadth & & 0.184 & 0.377 & 0.487 & 0.629 \\
\hline & Temperature variation & & -0.019 & 0.039 & -0.479 & 0.634 \\
\hline & Movement (partial) & & 0.133 & 0.086 & 1.542 & 0.129 \\
\hline & Movement (resident) & & 0.186 & 0.083 & 2.227 & 0.030 \\
\hline & Movement (migrant) & & 0.185 & 0.115 & 1.611 & 0.113 \\
\hline \multirow{6}{*}{ EIH (PPC) } & Body size & \multirow{6}{*}{ @̊+ } & 0.605 & 0.034 & 17.952 & $<0.001$ \\
\hline & Diet breadth & & 0.392 & 0.398 & 0.984 & 0.331 \\
\hline & PPC1 & & 0.013 & 0.006 & 2.207 & 0.033 \\
\hline & PPC2 & & 0.031 & 0.015 & 2.072 & 0.045 \\
\hline & Movement (partial) & & 0.054 & 0.061 & 0.887 & 0.381 \\
\hline & Movement (resident) & & -0.006 & 0.085 & -0.075 & 0.940 \\
\hline \multirow{6}{*}{ SIH } & Body size & \multirow{6}{*}{$\stackrel{\infty}{\stackrel{0}{0}}$} & 0.668 & 0.029 & 22.685 & $<0.001$ \\
\hline & Cooperative breeding (binary) & & -0.072 & 0.053 & -1.358 & 0.180 \\
\hline & Social foraging (nested pairs) & & 0.079 & 0.061 & 1.292 & 0.202 \\
\hline & Social foraging (solitary) & & 0.111 & 0.075 & 1.473 & 0.147 \\
\hline & $\begin{array}{l}\text { Social foraging (non-nested small } \\
\text { groups) }\end{array}$ & & 0.153 & 0.068 & 2.238 & $\mathbf{0 . 0 3 0}$ \\
\hline & $\begin{array}{l}\text { Social foraging (nested small } \\
\text { groups) }\end{array}$ & & 0.062 & 0.111 & 0.560 & 0.578 \\
\hline \multirow{11}{*}{$\begin{array}{l}\text { Combined (EIH } \\
+\mathrm{SIH})\end{array}$} & Body size & \multirow{11}{*}{ 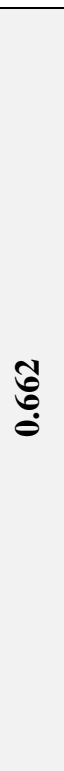 } & 0.658 & 0.031 & 21.565 & $<0.001$ \\
\hline & Diet breadth & & 0.161 & 0.389 & 0.414 & 0.680 \\
\hline & Temperature variation & & 0.000 & 0.038 & -0.001 & 0.999 \\
\hline & Movement (partial) & & 0.070 & 0.863 & 0.812 & 0.421 \\
\hline & Movement (resident) & & 0.173 & 0.082 & 2.0967 & 0.041 \\
\hline & Movement (migrant) & & -0.018 & 0.135 & -0.132 & 0.896 \\
\hline & Cooperative breeding (binary) & & -0.079 & 0.055 & -1.430 & 0.159 \\
\hline & Social foraging (nested pairs) & & 0.120 & 0.061 & 1.966 & 0.055 \\
\hline & Social foraging (solitary) & & 0.226 & 0.099 & 2.291 & 0.027 \\
\hline & $\begin{array}{l}\text { Social foraging (non-nested small } \\
\text { groups) }\end{array}$ & & 0.165 & 0.070 & 2.363 & 0.022 \\
\hline & $\begin{array}{l}\text { Social foraging (nested small } \\
\text { groups) }\end{array}$ & & 0.112 & 0.114 & 0.981 & 0.332 \\
\hline
\end{tabular}


312 Social variables also changed in significance depending on model specification. In the SIH

313 model, species that forage in non-nested small groups were shown to have significantly larger

314 brains than species that forage in pairs. In the combined model, with both social and

315 ecological variables included, solitary foragers and species that forage in non-nested small

316 groups were shown to have significantly larger brains than species that forage in pairs.

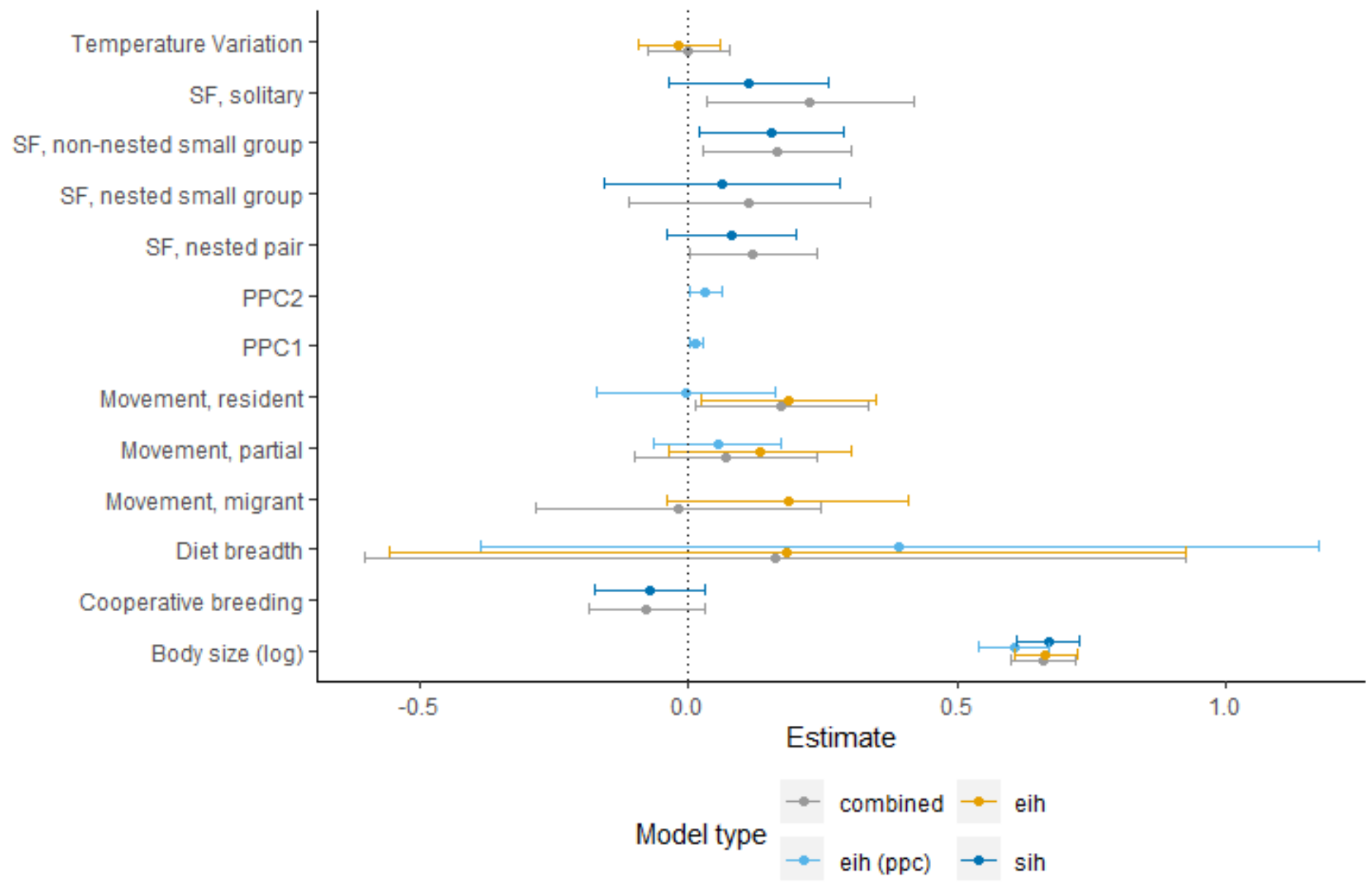

Figure 2 Estimates and confidence intervals for covariates (y axis) generated by models with differing variable combinations (see Table 1). SF = Social Foraging.

317 Changing facultative or suspected cooperative breeders from their initial categorisation of

318 cooperative breeders to non-cooperative breeders did not qualitatively change SIH model

319 results. However, changing partial migrants to residents did change EIH model results. For

320 the EIH model with PPCs, PPC1 and PPC2 changed from significantly influencing brain size

$321 \quad(\mathrm{PPC} 1: \beta=0.01, \mathrm{SE}=0.01 ; 95 \% \mathrm{CI}[0.001,0.03] ; p=0.03 ; \mathrm{PPC} 2: \beta=0.03 ; \mathrm{SE}=0.02 ; 95 \%$

$322 \mathrm{CI}[0.002,0.06] ; \mathrm{p}=0.04)$ to having no significant effect $(\mathrm{PPC} 1: \beta=0.01, \mathrm{SE}=0.01 ; 95 \%$

$323 \mathrm{CI}[0.0001,0.02] ; \mathrm{p}=0.055 ; \mathrm{PPC} 2: \beta=0.03, \mathrm{SE}=0.01 ; 95 \% \mathrm{CI}[-0.002,0.06] ; \mathrm{p}=0.07)$. 
In the combined model, where both changed variables were included, solitary foraging (relative to foraging in pairs) changed from having a significant $(\beta=0.23, \mathrm{SE}=0.10 ; 95 \%$ $\mathrm{CI}[0.09,0.37] ; \mathrm{p}=0.03)$ to no significant effect on brain size $(\beta=0.16, \mathrm{SE}=0.10 ; 95 \% \mathrm{CI}[-$ $0.03,0.35] ; \mathrm{p}=0.11)$.

Note, however, that although results were unstable in regards to significance, and thus in qualitative conclusions, effect sizes and confidence intervals were not drastically different between models.

\section{Discussion}

In agreement with a growing body of literature (Healy \& Rowe, 2007; Logan et al., 2018; Powell et al., 2017; Wartel et al., 2019), our analyses raise concerns that comparative brain size studies are not methodologically robust. We show that there is considerable variation in bird brain and body size estimates across datasets (Figure 1), most likely due to intraspecific variation. The most common methods of comparative brain size analysis do not take this variation into account, although it has the potential to substantially influence results. The combination, source and classification of social and ecological variables also changed results substantially (Figure 2). Indeed, we could have come to several contradictory conclusions depending on our modelling approach. Our results chime with and add to concerns raised in the primate brain size literature (Powell et al., 2017; Wartel et al., 2019) that current methods in the comparative study of brain size evolution give unreliable results.

Comparative brain size studies typically use brain and body sizes averaged from multiple specimens of a single species to obtain one brain and body size estimate per species. Despite all brain sizes in our sample being estimated either from endocranial volume, or brain mass converted to volume (which results in a strong positive correlation with volume measurements (Iwaniuk \& Nelson, 2002)), we found substantial variation in brain size estimates across datasets. In several extreme cases, the minimum and maximum brain size measures for one species overlapped with $10 \%$ of our sample. Similarly, we found considerable variation between body size estimates of the same species: in extreme cases, the minimum and maximum body size of a species overlapped with more than $30 \%$ of the species in our sample. Variation in brain and body size was not driven by any dataset in particular, suggesting that it was not the result of a specific methodological approach, but rather the result of natural intraspecific variation in brain and body size, the use of different specimens by different studies, and the small sample sizes used to obtain estimates. Often, 
key information about where estimates were derived from was not reported. For instance, the sex of specimens and the variation around the single reported estimate was not reported for most brain size datasets. Body size estimates had even sparser associated information: in most cases, the number of specimens from which the estimate was derived was not given, and neither was sex or variation around the estimate. The fact that estimates tend to be derived from few (or an unknown number of) specimens, often of unrecorded sex, raises concerns as to how well they represent species-average values. Indeed, our study suggests that results of comparative brain size have the potential to be substantially influenced by the brain and body size dataset used, given the variation between estimates.

In addition to investigating variation in brain and body size estimates across datasets, we interrogated how robust models are depending on variable combination, source and classification. Researchers typically have varying approaches to model building, and in agreement with Wartel et al.'s (2019) analyses of primate brain size data, we found that modelling approach influenced results. For instance, depending on whether we chose to include social variables or social and ecological variables, we could have concluded that there is no difference in brain size between species that forage in pairs and species that forage solitarily or that species that forage solitarily have significantly larger brains than those that forage in pairs. In addition, we showed that the source of covariates has the potential to substantially change results. Using temperature variation from Fristoe et al. (2017) as a proxy of environmental variation resulted in no support that environmental variation drives the evolution of bigger brains. Meanwhile, using more detailed measures of environmental variation from Sayol et al. (2016) resulted in support. Note, however, that models with temperature variation rather than PPC had a larger sample size, which may influence these results. Nevertheless, these findings parallel those reported in the primate brain size literature (Powell et al., 2017), where using differing variable sources resulted in differing results even when sample sizes were matched. Moreover, we show that variable classification can also drastically influence results. Classifications of variables are sometimes subjective; for instance, species with both cooperatively and non-cooperatively breeding populations could be classified as either. We therefore changed categorical variables that could justifiably be reclassified, and tested how this influenced results. Re-classifying suspected/facultative cooperative breeders as non-cooperative breeders did not change SIH model results; however, re-classifying partial migrants (i.e., where at least one population of a species migrate) as residents substantially changed EIH model results. While two measures of environmental 
variation (PPC1 and PPC2) were significantly associated with bigger brains before reclassification, there was no significant effect following re-classification. Thus, depending on the classification of a different model covariate, we could have concluded that environmental variation is associated with bigger brains or that there is no association. It must be considered, however, that while p-values crossed the threshold of significance, estimates and confidence intervals for predictor variables did not substantially change. With larger sample sizes, models may be less volatile. Nevertheless, many studies of brain size evolution use sample sizes in the same range as ours (e.g. Schillaci, 2006; Shultz \& Dunbar, 2007; Uomini et al., 2020; Vincze, 2016; West, 2014). The concerns raised here are thus pertinent to a wide range of studies.

Taken together, our investigations show that brain and body size data can vary widely between datasets, and that variable combination, source and classification can result in contradictory conclusions depending on somewhat subjective decisions made by researchers. In conjunction with previous work highlighting problems with comparative brain size models (Healy \& Rowe, 2007; Logan et al., 2018; Powell et al., 2017; Wartel et al., 2019), this throws previous claims of support for the SIH (e.g., Dunbar, 1992; Shultz \& Dunbar, 2010) or the EIH (e.g., DeCasien et al., 2017) into question. In addition to issues with methodological approach, we argue that framing the SIH and EIH as dichotomous and competing hypotheses is not logically sound. We give two reasons for this. First, the hypothesised underlying driver of cognitive evolution for both hypotheses is variation in environmental conditions (including social environment) in which individuals must gather and process information to mitigate uncertainty (Dall et al., 2005; Dunlap \& Stephens, 2016). Second, social and ecological variables are not independent, i.e., social species solve ecological problems in a social context, and sociality itself may evolve in response to ecological variables (Ashton, Thornton, et al., 2018; Jetz \& Rubenstein, 2011). We therefore suggest not only that our methodological approach to studying comparative brain size evolution needs to change, but also the conceptual framework itself. Rather than splitting often-correlated variables into dichotomous and competing predictors, we could benefit from quantifying the environmental uncertainty animals face in specific contexts and examining how this may drive cognitive evolution.

When considering the accumulating literature on issues associated with comparative studies of brain size evolution (here; Healy \& Rowe, 2007; Logan et al., 2018; Powell et al., 2017; Wartel et al., 2019), we add our voices to a growing number in the field suggesting that we 
move away from such methods to interrogate comparative cognition, and towards a more robust approach that researchers may wish to consider instead. For instance, a fruitful way forward may be to ask how uncertainty in the social and ecological environment influences cognitive performance at the intra-specific level (Ashton, Ridley, et al., 2018; Ashton, Thornton, et al., 2018; Morand-Ferron et al., 2016; Thornton et al., 2014), and between closely related species (Bond et al., 2003; Maclean et al., 2008; MacLean et al., 2013; Sandel et al., 2011; Sheehan \& Tibbetts, 2011). Conceptually, we recommend a shift away from treating the SIH and EIH as dichotomous hypotheses; instead, we propose that we should work to understand whether and how uncertainty across a range of contexts drives cognitive evolution.

\section{Literature cited}

Allman, J. M., McLaughlin, T., \& Hakeem, A. (1993). Brain structures and life-span in primate species. Proceedings of the National Academy of Sciences of the United States of America, 90(8), 3559-3563. https://doi.org/10.1073/pnas.90.8.3559

Ashton, B. J., Kennedy, P., \& Radford, A. N. (2020). Interactions with conspecific outsiders as drivers of cognitive evolution. Nature Communications, 11(1), 1-9. https://doi.org/10.1038/s41467-020-18780-3

Ashton, B. J., Ridley, A. R., Edwards, E. K., \& Thornton, A. (2018). Cognitive performance is linked to group size and affects fitness in Australian magpies. Nature, 554(7692), 364-367. https://doi.org/10.1038/nature25503

Ashton, B. J., Thornton, A., \& Ridley, A. R. (2018). An intraspecific appraisal of the social intelligence hypothesis. Philosophical Transactions of the Royal Society B, 373, 20170288. https://doi.org/http://dx.doi.org/10.1098/rstb.2017.0288

Barton, R. A. (1996). Neocortex size and behavioural ecology in primates. Proceedings of the Royal Society B: Biological Sciences, 263(1367), 173-177. https://doi.org/10.1098/rspb.1996.0028

Bond, A. B., Kamil, A. C., \& Balda, R. P. (2003). Social complexity and transitive inference in corvids. Animal Behaviour, 65(3), 479-487. https://doi.org/10.1006/anbe.2003.2101

Boucherie, P. H., Loretto, M. C., Massen, J. J. M., \& Bugnyar, T. (2019). What constitutes "social complexity" and "social intelligence" in birds? Lessons from ravens. Behavioral 
Burkart, J. M., Hrdy, S. B., \& Van Schaik, C. P. (2009). Cooperative breeding and human cognitive evolution. Evolutionary Anthropology, 18(5), 175-186. https://doi.org/10.1002/evan.20222

Burkart, J. M., \& van Schaik, C. P. (2009). Cognitive consequences of cooperative breeding in primates? Animal Cognition, 13(1), 1-19. https://doi.org/10.1007/s10071-009-0263-7

Byrne, R. W., \& Whiten, A. (1988). Machiavellian Intelligence. Clarendon Press.

Chen, M., Li, G., Liu, J., \& Li, S. (2021). Large brain size is associated with low extra-pair paternity across bird species. Ecology and Evolution, August, 1-8. https://doi.org/10.1002/ece3.8087

Chittka, L., \& Niven, J. (2009). Are Bigger Brains Better? Review. Current Biology, 19(21), R995-R1008. https://doi.org/10.1016/j.cub.2009.08.023

Clutton-Brock, T. H., \& Harvey, P. H. (1980). Primates, brains and ecology. Journal of Zoology, 190(3), 309-323. https://doi.org/10.1111/j.1469-7998.1980.tb01430.x

Corfield, J. R., Birkhead, T. R., Spottiswoode, C. N., Iwaniuk, A. N., Boogert, N. J., Gutiérrez-Ibáñez, C., Overington, S. E., Wylie, D. R., \& Lefebvre, L. (2013). Brain size and morphology of the brood-parasitic and cerophagous honeyguides (Aves: Piciformes). Brain, Behavior and Evolution, 81(3), 170-186. https://doi.org/10.1159/000348834

Dall, S. R. X., Giraldeau, L., Olsson, O., Mcnamara, J. M., \& Stephens, D. W. (2005). Information and its use by animals in evolutionary ecology. Trends in Ecology and Evolution, 20(4). https://doi.org/10.1016/j.tree.2005.01.010

de Cáceres, M., Sol, D., Lapiedra, O., \& Legendre, P. (2011). A framework for estimating niche metrics using the resemblance between qualitative resources. Oikos, 120(9), 13411350. https://doi.org/10.1111/j.1600-0706.2011.19679.x

Deaner, R. O, Barton, R. A., \& van Schaik, C. P. (2003). Primate brains and life histories: Renewing the connection. In P. M. Kappeler \& M. E. Pereira (Eds.), Primate Life Histories and Socioecology (Issue January, pp. 233-265). The University of Chicago Press. 

$\mathrm{q}=$ primate+brains+and+life+history+deaner\&ots=TBSiV2y1Wv\&sig=nQ3IHStXZwtE KcjKcYJyPIWjjBE\%5Cnpapers3://publication/uuid/A0033DF9-A410-4BCB-9EBBF120AA7D69BB

Deaner, R. O., van Schaik, C. P., \& Johnson, V. (2006). Do Some Taxa Have Better DomainGeneral Cognition than others? A Meta-Analysis of Nonhuman Primate Studies. Evolutionary Psychology, 4(1), 147470490600400. https://doi.org/10.1177/147470490600400114

DeCasien, A. R., Williams, S. A., \& Higham, J. P. (2017). Primate brain size is predicted by diet but not sociality. Nature Ecology \& Evolution, 1(5), 0112. https://doi.org/10.1038/s41559-017-0112

Dunbar, R. I. M. (1992). Neocortex size as a constraint size in primates on group ecologically. March 1989.

Dunbar, R. I. M. (1998). The Social Brain Hypothesis. Evolutionary Anthropology, 178-190. https://doi.org/10.1002/(SICI)1520-6505(1998)6:5<178::AID-EVAN5>3.3.CO;2-P

Dunbar, R. I. M., \& Shultz, S. (2017). Why are there so many explanations for primate brain evolution? Philosophical Transactions of the Royal Society of London. Series B, Biological Sciences, 372(1727), 20160244. https://doi.org/10.1098/rstb.2016.0244

Dunlap, A. S., \& Stephens, D. W. (2016). Reliability, uncertainty, and costs in the evolution of animal learning. Current Opinion in Behavioral Sciences, 12, 73-79. https://doi.org/10.1016/j.cobeha.2016.09.010

Emery, N. J., Seed, A., Bayern, A. M. P. Von, \& Clayton, N. S. (2007). Cognitive adaptations of social bonding in birds. Philosophical Transactions of the Royal Society B, 362(1480), 489-505. https://doi.org/10.1098/rstb.2006.1991

Fristoe, T. S., \& Botero, C. A. (2019). Alternative ecological strategies lead to avian brain size bimodality in variable habitats. Nature Communications, 10(1). https://doi.org/10.1038/s41467-019-11757-x

Fristoe, T. S., Iwaniuk, A. N., \& Botero, C. A. (2017). Big brains stabilize populations and facilitate colonization of variable habitats in birds. Nature Ecology and Evolution, 1(11), 1706-1715. https://doi.org/10.1038/s41559-017-0316-2 
size in relation to prey capture and nocturnality. Proceedings of the Royal Society B: Biological Sciences, 269(1494), 961-967. https://doi.org/10.1098/rspb.2002.1967

García-Peña, G. E., Sol, D., Iwaniuk, A. N., \& Székely, T. (2013). Sexual selection on brain size in shorebirds (Charadriiformes). Journal of Evolutionary Biology, 26(4), 878-888. https://doi.org/10.1111/jeb.12104

Güntürkün, O., \& Bugnyar, T. (2016). Cognition without Cortex. Trends in Cognitive Sciences, 20(4), 291-303. https://doi.org/10.1016/j.tics.2016.02.001

Harvey, P. H., \& Krebs, J. R. (1990). Comparing brains. In Science (Vol. 249, Issue 4965, pp. 140-146). https://doi.org/10.1126/science.2196673

Healy, S. D., \& Rowe, C. (2007). A critique of comparative studies of brain size. In Proceedings of the Royal Society B: Biological Sciences (Vol. 274, Issue 1609, pp. 453464). https://doi.org/10.1098/rspb.2006.3748

Holekamp, K. E. (2007). Questioning the social intelligence hypothesis. Trends in Cognitive Sciences, 11(2), 65-69. https://doi.org/10.1016/j.tics.2006.11.003

Hrdy, S. B. (2009). Mother Nature: A History of Mothers, Infants, and Natural Selection. Harvard University Press.

Humphrey, N. K. (1976). The social function of intellect. Growing Points in Ethology, 37(5), 303-317. https://doi.org/10.2307/375925

Iwaniuk, A. N. (2004). Brood Parasitism and Brain Size in Cuckoos: A Cautionary Tale on the Use of Modern Comparative Methods. International Journal of Comparative Psychology, 17, 17-33.

Iwaniuk, A. N., \& Arnold, K. E. (2004). Is cooperative breeding associated with bigger brains? A comparative test in the Corvida (Passeriformes). Ethology, 110(3), 203-220. https://doi.org/10.1111/j.1439-0310.2003.00957.x

Iwaniuk, A. N., Dean, K. M., \& Nelson, J. E. (2004). A mosaic pattern characterizes the evolution of the avian brain. Proceedings of the Royal Society B: Biological Sciences, 271(SUPPL. 4), 148-151. https://doi.org/10.1098/rsbl.2003.0127

Iwaniuk, A. N., Dean, K. M., \& Nelson, J. E. (2005). Interspecific allometry of the brain and brain regions in parrots (Psittaciformes): Comparisons with other birds and primates. 
Iwaniuk, A. N., \& Nelson, J. E. (2002). Can endocranial volume be used as an estimate of brain size in birds? Canadian Journal of Zoology, 80(1), 16-23. https://doi.org/10.1139/z01-204

Iwaniuk, A. N., \& Nelson, J. E. (2003). Developmental differences are correlated with relative brain size in birds: a comparative analysis. Canadian Journal of Zoology, 81(12), 1913-1928. https://doi.org/10.1139/z03-190

Jetz, W., \& Rubenstein, D. R. (2011). Environmental uncertainty and the global biogeography of cooperative breeding in birds. Current Biology, 21(1), 72-78. https://doi.org/10.1016/j.cub.2010.11.075

Jolly, A. (1966). Lemur social behavior and primate intelligence. Science, 153(3735), 501506. https://doi.org/10.1126/science.153.3735.501

Jønsson, K. A., Fabre, P. H., Kennedy, J. D., Holt, B. G., Borregaard, M. K., Rahbek, C., \& Fjeldså, J. (2016). A supermatrix phylogeny of corvoid passerine birds (Aves: Corvides). Molecular Phylogenetics and Evolution, 94, 87-94. https://doi.org/10.1016/j.ympev.2015.08.020

Ksepka, D. T., Balanoff, A. M., Smith, N. A., Bever, G. S., Bhullar, B. A. S., Bourdon, E., Braun, E. L., Burleigh, J. G., Clarke, J. A., Colbert, M. W., Corfield, J. R., Degrange, F. J., De Pietri, V. L., Early, C. M., Field, D. J., Gignac, P. M., Gold, M. E. L., Kimball, R. T., Kawabe, S., ... Smaers, J. B. (2020). Tempo and Pattern of Avian Brain Size Evolution. Current Biology, 30(11), 2026-2036.e3. https://doi.org/10.1016/j.cub.2020.03.060

Lendvai, Á. Z., Bókony, V., Angelier, F., Chastel, O., \& Sol, D. (2013). Do smart birds stress less? An interspecific relationship between brain size and corticosterone levels. Proceedings of the Royal Society B: Biological Sciences, 280(1770). https://doi.org/10.1098/rspb.2013.1734

Logan, C. J., Avin, S., Boogert, N., Buskell, A., Cross, F. R., Currie, A., Jelbert, S., Lukas, D., Mares, R., Navarrete, A. F., Shigeno, S., \& Montgomery, S. H. (2018). Beyond brain size: Uncovering the neural correlates of behavioral and cognitive specialization. Comparative Cognition and Behavior Reviews, 13, 55-90. 
Lukas, D., \& Clutton-Brock, T. (2018). Social complexity and kinship in animal societies. Ecology Letters, 21(8), 1129-1134. https://doi.org/10.1111/ele.13079

574

575

576

MacLean, E. L., Barrickman, N. L., Johnson, E. M., \& Wall, C. E. (2009). Sociality, ecology, and relative brain size in lemurs. Journal of Human Evolution, 56(5), 471-478. https://doi.org/10.1016/j.jhevol.2008.12.005

MacLean, E. L., Sandel, A. A., Bray, J., Oldenkamp, R. E., Reddy, R. B., \& Hare, B. A. (2013). Group Size Predicts Social but Not Nonsocial Cognition in Lemurs. PLoS ONE, 8(6), 1-9. https://doi.org/10.1371/journal.pone.0066359

Maclean, E. L., Tin, D. U. S., Ritt, J. M. E. R., \& Non, E. M. B. (2008). Social complexity predicts transitive reasoning in prosimian primates. 479-486. https://doi.org/10.1016/j.anbehav.2008.01.025

Minias, P., \& Podlaszczuk, P. (2017). Longevity is associated with relative brain size in birds. Ecology and Evolution, 7(10), 3558-3566. https://doi.org/10.1002/ece3.2961

Morand-Ferron, J., Cole, E. F., \& Quinn, J. L. (2016). Studying the evolutionary ecology of cognition in the wild: A review of practical and conceptual challenges. Biological Reviews, 91(2), 367-389. https://doi.org/10.1111/brv.12174

Overington, S. E., Morand-Ferron, J., Boogert, N. J., \& Lefebvre, L. (2009). Technical innovations drive the relationship between innovativeness and residual brain size in birds. Animal Behaviour, 78(4), 1001-1010. https://doi.org/10.1016/j.anbehav.2009.06.033

Pérez-Barbería, F. J., Shultz, S., \& Dunbar, R. I. M. (2007). Evidence for coevolution of sociality and relative brain size in three orders of mammals. Evolution, 61(12), 28112821. https://doi.org/10.1111/j.1558-5646.2007.00229.x

Powell, L. E., Isler, K., Barton, R. A., Powell, L. E., \& Barton, R. A. (2017). Re-evaluating the link between brain size and behavioural ecology in primates. Proc Royal Soc, 1-8.

Pravosudov, V. V., Sanford, K., \& Hahn, T. P. (2007). On the evolution of brain size in relation to migratory behaviour in birds. Animal Behaviour, 73(3), 535-539. https://doi.org/10.1016/j.anbehav.2006.10.005 
600

601

602

603

604

605

606

607

608

609

610

611

612

613

614

615

616

617

618

619

620

621

622

623

624

625

626

627

628

629

Rosati, A. G. (2017). Foraging Cognition: Reviving the Ecological Intelligence Hypothesis. Trends in Cognitive Sciences, 21(9), 691-702. https://doi.org/10.1016/j.tics.2017.05.011

Sandel, A. A., MacLean, E. L., \& Hare, B. (2011). Evidence from four lemur species that ringtailed lemur social cognition converges with that of haplorhine primates. Animal Behaviour, 81(5), 925-931. https://doi.org/10.1016/j.anbehav.2011.01.020

Sayol, F., Maspons, J., Lapiedra, O., Iwaniuk, A. N., Székely, T., \& Sol, D. (2016). Environmental variation and the evolution of large brains in birds. Nature Communications, 7. https://doi.org/10.1038/ncomms13971

Schillaci, M. A. (2006). Sexual selection and the evolution of brain size in primates. PLoS ONE, 1(1), 1-5. https://doi.org/10.1371/journal.pone.0000062

Schmidt, K. A., Dall, S. R. X., \& van Gils, J. A. (2010). The ecology of information: An overview on the ecological significance of making informed decisions. Oikos, 119(2), 304-316. https://doi.org/10.1111/j.1600-0706.2009.17573.x

Schuck-paim, C., Alonso, W. J., \& Ottoni, B. (2008). Cognition in an Ever-Changing World : Climatic Variability Is Associated with Brain Size in Neotropical Parrots. Brain, Behavior and Evolution, 71, 200-215. https://doi.org/10.1159/000119710

Seed, A., Emery, N. J., \& Clayton, N. S. (2009). Intelligence in corvids and apes: A case of convergent evolution? Ethology, 115(5), 401-420. https://doi.org/10.1111/j.14390310.2009.01644.x

Sheehan, M. J., \& Tibbetts, E. A. (2011). Specialized face learning is associated with individual recognition in paper wasps. Science, 334(6060), 1272-1275. https://doi.org/10.1126/science.1211334

Shultz, S., \& Dunbar, R. I. M. (2007). The evolution of the social brain: anthropoid primates contrast with other vertebrates. Proceedings of the Royal Society B: Biological Sciences, 274(1624), 2429-2436. https://doi.org/10.1098/rspb.2007.0693

Shultz, S., \& Dunbar, R. I. M. (2010). Social bonds in birds are associated with brain size and contingent on the correlated evolution of life-history and increased parental investment. Biological Journal of the Linnean Society, 100(1), 111-123. https://doi.org/10.1111/j.1095-8312.2010.01427.x

Sol, D., Garcia, N., Iwaniuk, A., Davis, K., Meade, A., Boyle, W. A., \& Székely, T. (2010). 
Evolutionary divergence in brain size between migratory and resident birds. PLoS ONE, 5(3), 1-8. https://doi.org/10.1371/journal.pone.0009617

Street, S. E., Navarrete, A. F., Reader, S. M., \& Laland, K. N. (2017). Coevolution of cultural intelligence, extended life history, sociality, and brain size in primates. Proceedings of the National Academy of Sciences, 114(30), 7908-7914. https://doi.org/10.1073/pnas.1620734114

Thornton, A., Isden, J., \& Madden, J. R. (2014). Toward wild psychometrics: Linking individual cognitive differences to fitness. Behavioral Ecology, 25(6), 1299-1301. https://doi.org/10.1093/beheco/aru095

Thornton, A., \& McAuliffe, K. (2015). Cognitive consequences of cooperative breeding? A critical appraisal. 295, 12-22. https://doi.org/10.1111/jzo.12198

Thornton, A., Mcauliffe, K., Dall, S. R. X., Fernandez-Duque, E., Garber, P. A., \& Young, A. J. (2016). Fundamental problems with the cooperative breeding hypothesis. A reply to Burkart \& van Schaik. Journal of Zoology, 299(2), 84-88. https://doi.org/10.1111/jzo.12351

Uomini, N., Fairlie, J., Gray, R. D., \& Griesser, M. (2020). Extended parenting and the evolution of cognition. Philosophical Transactions of the Royal Society B: Biological Sciences, 375(1803). https://doi.org/10.1098/rstb.2019.0495

van Woerden, J. T., van Schaik, C. P., \& Isler, K. (2010). Effects of Seasonality on Brain Size Evolution: Evidence from Strepsirrhine Primates. The American Naturalist, 176(6), 758-767. https://doi.org/10.1086/657045

Vincze, O. (2016). Light enough to travel or wise enough to stay? Brain size evolution and migratory behavior in birds. Evolution; International Journal of Organic Evolution, 70(9), 2123-2133. https://doi.org/10.1111/evo.13012

Wartel, A., Lindenfors, P., \& Lind, J. (2019). Whatever you want: Inconsistent results are the rule, not the exception, in the study of primate brain evolution. PLoS ONE, 14(7), 1-15. https://doi.org/10.1371/journal.pone.0218655

West, R. (2014). The evolution of large brain size in birds is related to social, not genetic , monogamy social, not genetic , monogamy. Biological Journal of the Linnean Society, 111, 668-678. https://doi.org/10.1111/bij.12193 
bioRxiv preprint doi: https://doi.org/10.1101/2021.11.25.469898; this version posted November 29, 2021. The copyright holder for this preprint (which was not certified by peer review) is the author/funder, who has granted bioRxiv a license to display the preprint in perpetuity. It is made available under aCC-BY-NC-ND 4.0 International license. 